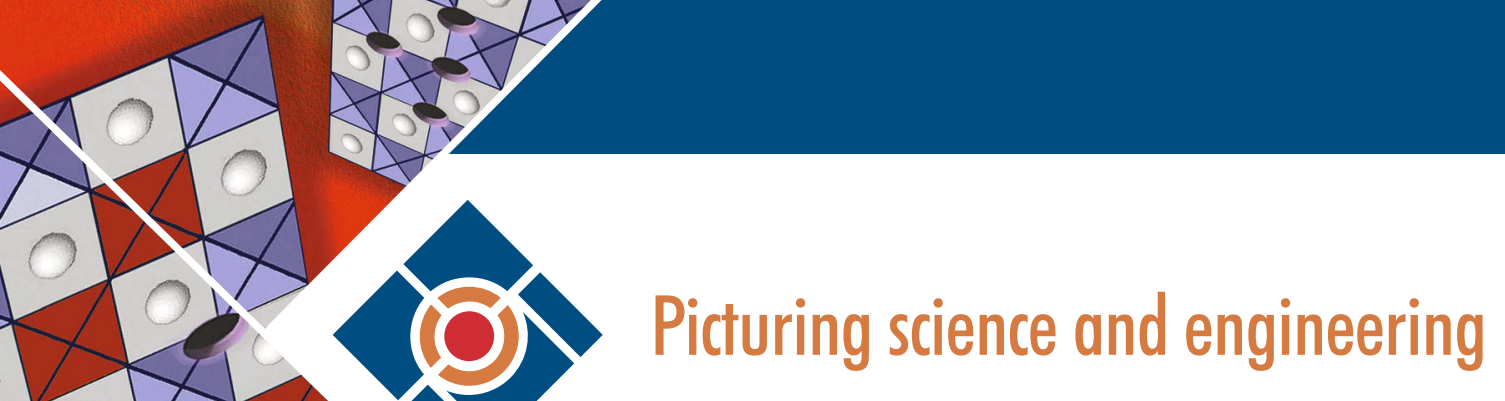

Felice C. Frankel

Submitted May 26, 2020; Accepted June 9, 2020

W hen I began writing this article, it was just the beginning of COVID-19, when we were not yet social distancing. Everything has changed since then, but not a conviction I have disseminated for more than 25 years. More than ever, I maintain that formally addressing the critical visual component of research should be part of every researcher's education. How you visually represent your work not only communicates to others in your discipline. Crafting your visual presentations helps clarify your own thinking and, just as important, is a means of engaging the public. In these challenging times, when society is bombarded with complex information, it is more essential than ever to develop a more accessible and honest visual "language" for the public to understand and gather that information. Formal programs in teaching visual communication will help show the world, outside the research community, how to look at science, understand it, question it, and, hopefully, make smart decisions.

Many of you might be putting part of your research on a temporary hold, especially those at the benches. The theoretical and computational researchers are probably still in business. My own campus has been ramping up research, and it is apparent laboratories will be redefined for the time being. Perhaps theoretical and computational researchers will not be as restricted. But for the rest, I can only imagine how this pandemic has and will continue to affect work in laboratories. Science is already a slow enterprise, and it takes a certain type of person who enters its world. She knows too well that gathering meaningful data from experiments can only be done with time and patience. That patience will be tested even further when the anticipated limits because of COVID continue to be put in place. I wonder if the challenges of doing research in the future will result in a significant drop in the number of students entering graduate programs in science and engineering. They might choose, perhaps, the more computational road not because of disinterest in experimentation, but out of pragmatism. Then again, the upward swing of using computation in all kinds of research has already begun. Perhaps, building on that groundwork will help keep the labs running and attract even more students as we return to some sort of normalcy.

But, wherever you land, think about this. When you read the title and abstract of a particular journal article, do you immediately begin reading the article, or do you first take a look at the figures right after reading the abstract? I often ask that question to my students in our MIT workshops on visual communication, and they agree that they do, in fact, go right to the figures. My colleague Alyssa Goodman, professor of astronomy at Harvard University, is as passionate about the importance of communicative visualizations as I. She ran an informal survey of students with 276 responses. The question was "When do you usually look at the figures in a paper?" The response: $55.1 \%$ said that they, "look at the figures after reading the titles and abstract;" 14.9\% "mostly look at the figures and read some text while doing that." That's $70 \%$ of the responses, indicating the importance of the figures when reading an article. If that is the case, then why leave your graphics, an essential part of any article, for the last minute when submitting to a journal? Why not give the graphics the same consideration as the text?

I have had the privilege of collaborating with researchers on the visual components of their work for many years. Mostly, I make evidence-based photographs of science (Figures 1 and 2). 
Lately, I assemble pieces of my photographs, creating metaphors to explain complicated phenomena (Figure 3).

I also work collaboratively with scientists and engineers to develop their figures for journal submissions (Figure 4). Although these researchers come from a broad spectrum of disciplines, I have observed universal decision challenges, crossing all boundaries:

How best can we use color, composition, and labeling?

- How can we create a hierarchy of information to help the reader "travel" through the figure?

-What metaphor or analogy works best?

-Will an animation explain it better?

- Shall we start making the data interactive?

Unfortunately, the prevailing problem is that most researchers assume we easily see what they want us to see. That is often not the case. As we page through the figures in an article or watch a presentation while we sit in an audience, we usually see so much information that we don't bother to look, or we have to work too hard to get the point. Showing all of your data in one figure doesn't help us see. Often, pieces in the figures are image redundancies, because a researcher wants to display all of the SEMs he created. Extra images do not better communicate the material. In fact, they simply take up too much space with no new information. Crowding every inch of the slide with graphical distractions doesn't help either. I ask my students what can you edit from your figure or slide, in other words, what are the most important components? They are always surprised that they can, in fact, simplify the graphic. I sometimes cringe when I see slides presented by highly accomplished principal investigators (PIs). Most do not understand that I, the viewer in the audience, am seeing the material for the first time, and that I don't know where to look. To make things worse, there is often so much text, typically different from the presenter's spoken words, it makes my head spin. I would rather look away. I wonder how often presenters actually view their slides from the audience's point of view?

Thankfully, this new generation of researchers understands the value of visual clarity, and they are paying more attention to the communicative nature of their visuals. But unfortunately, their design decisions are mostly made ad hoc and informed mostly by their personal aesthetics. There is the occasional conversation addressing font size and color choices, but few delve into the deeper intention of how to communicate what they want to "say." More frustrating is when an early career researcher shows me her new idea of a particularly effective way of visually communicating an idea, but then she informs me that her PI objects because, "it's never done that way," stifling her thinking while he perpetuates faulty design concepts.

\section{Virtual workshops}

Before COVID-19, we had been running a series of residential workshops. For the time being, they are being held virtually, and interestingly, they have been quite successful, probably because the conversation is focused on one subject only (i.e., is the figure really working?). I measure workshop success

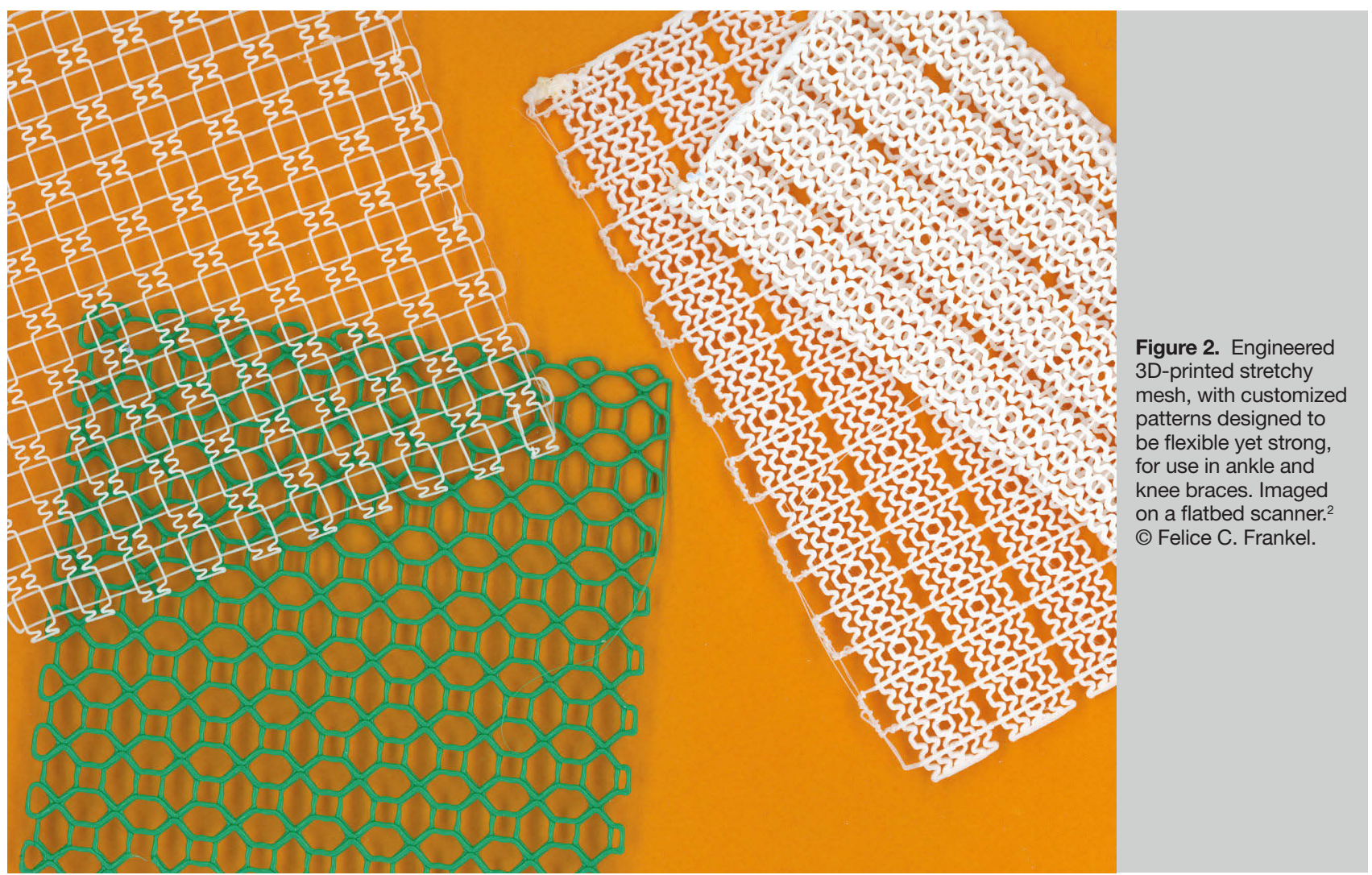




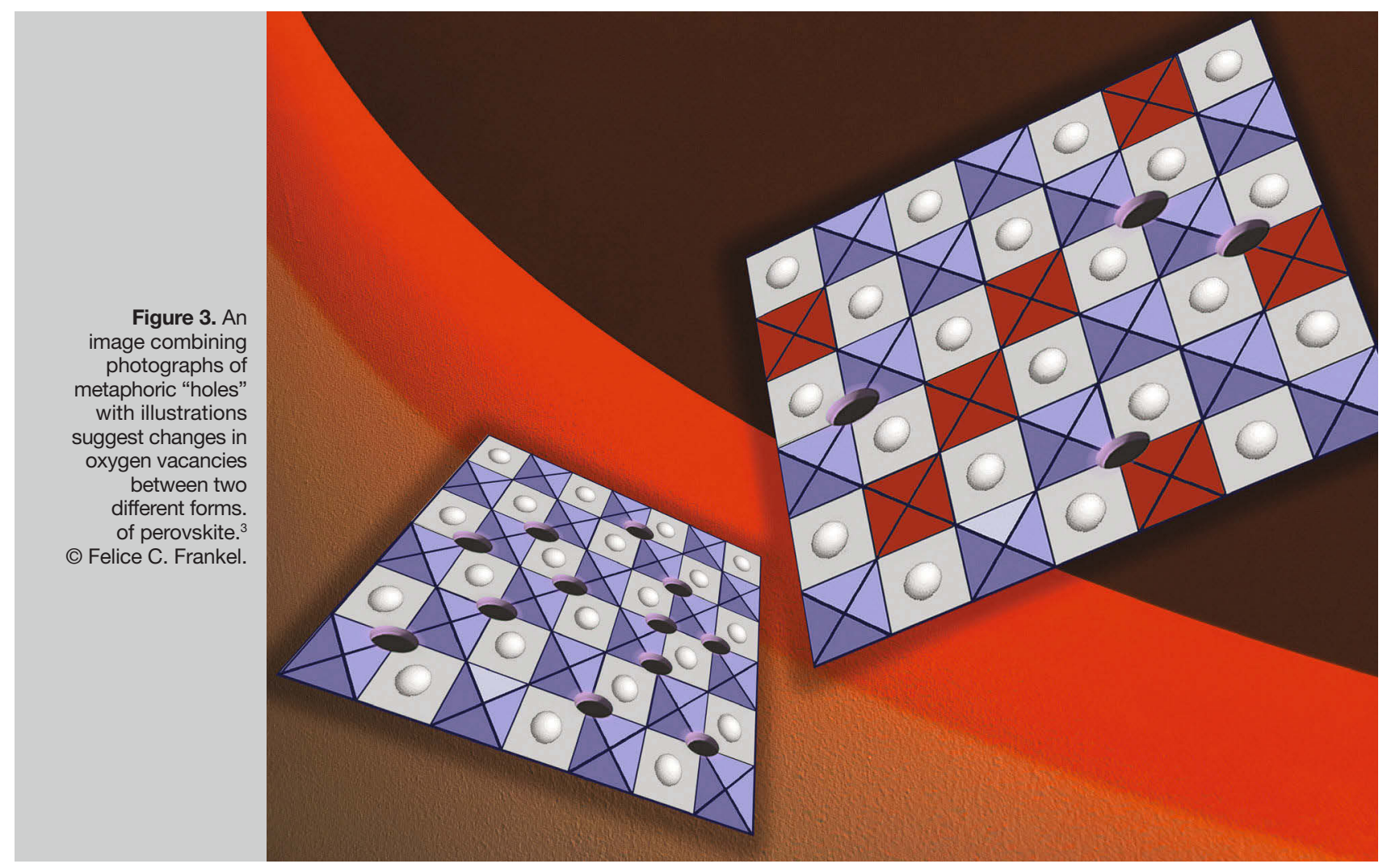

by the high level of active participation from each grad student or postdoc and the comments I receive after the workshop.

I encourage your group to run your own workshop. Keep in mind there needs to be someone who is not familiar with the research but is part of the research community or someone deeply curious and has a solid graphics background or keen interest. I play that role by (1) making graphical suggestions and (2) asking various questions that require the researcher to explain the science to me. Here is an outline of how we run ours.

1. The PI first announces the workshop.

2. Participants are asked to send to me, in advance, only one submission of a figure, image, cover submission, slide, poster, illustration, or table of contents (TOC) image. Files need to be in PDF, PowerPoint, Keynote, TIFF, or JPEG form. This gives me time to consider the issues.

3. We all meet via Zoom and go over each file, one by one. I sometimes include some of my "re-dos" of their submission in the presentation.

4. If the group has to meet asynchronously, I use VoiceThread. As we go through their draft figures, I ask a series of questions to the group in this order:

-Where does your eye land first? What do you see first?

Does the graphic show evidence?

$\checkmark$ Process?

$\checkmark$ Change?

Are you making a comparison?

• From the latter four, is your answer "all of the above"?
If your answer is all of the above, you are saying too much. Go back and rethink the graphic. The conversations then wander into the weeds - with each submission having specific "fixes" to consider.

-What can you leave out or put in supplemental information?

- Can you rethink the composition by moving things around?

- Why are you using a PowerPoint template and depending on someone else to determine the layout?

-Why are you using the software default for the color scheme?

We also get into lengthy discussions addressing image manipulation. It is an important subject not often discussed. I devote a full chapter to it in my book, Picturing Science and Engineering. ${ }^{4}$

If and when there is time, (and unfortunately, sometimes there isn't), I ask the participants to describe their work to a non-expert, encouraging them to think about what metaphor will work.

\section{Clarifying the science}

Ask any researcher, photographer, animator, or graphic designer who is working in science and engineering representation, and they will tell you that during the process, they have clarified the science in their own minds. Questioning this and that (e.g., Where should this piece go? Should I include that?) while making the visual encourages the researcher to think about the parts they had not yet considered. The clarification is productive when we think about creating a metaphor to visually explain concepts we cannot see. Finding the "right" metaphor is not trivial. The exercise gets even more interesting when the discussion includes where the metaphor fails. After all, all metaphors fall apart at some 
point. That conversation can often lead to pinpointing our misunderstandings. The process can also be a powerful new tool in teaching high school science. It could, perhaps, ultimately serve to motivate students to pursue advanced studies and careers in science and engineering.

\section{Undergraduate education}

From 2003-2010, we ran an NSF-funded program on four campuses, called Picturing to Learn. We asked 3000 undergrads to visually "explain" various phenomena they were learning in lecture classes. Many of the images were extraordinary (Figure 5). You can find them on the Picturing to Learn website.

The most interesting aspect of the program is that we discovered students' misconceptions. They might have gotten the right answer when asked to choose from a multiple choice list. But when we asked them to visually explain the answer, most of the students omitted the critical component(s) of the drawing. One of our professors wrote: "I was able to teach the material far better after seeing the students' drawings. ... They revealed misconceptions in a way that text does not... it became obvious when they didn't have a clue."

Each drawing was analyzed by trained teaching assistants, working from a rubric supplied by the instructor. Analyses of all drawings were then summarized.

For example, after a lecture on Brownian motion, students were asked the following: Draw, as if explaining to a high school student, how the motions of large and small particles suspended in a fluid are affected by an increase in temperature of the fluid. Professor's rubric:

$\checkmark$ Particles are different sizes.

- Temperature affects rate of movement of particles.

- Atoms/molecules that make up the liquid are in constant thermal motion; their velocity distribution (and/or mean kinetic energy) is determined by the temperature of the system.

- Moving atoms/molecules that make up the liquid strike the suspended particles at random, making them move randomly through the fluid.

- Particles are suspended in fluid and are larger than particles of the fluid.

$\diamond$ Drawing is correctly labeled.

From this class, $94.5 \%$ of the drawings were considered "problematic" (see Tables I-III). Total number of drawings: 110.
In every exercise, there were more "problematic" drawings than those that met the metric. When the grant ended, I approached my NSF program officer about expanding the effort. He told me the idea was interesting and successful up to a point, but that it was not scalable. He saw the program only for a "niche" audience.

That niche audience has grown to become the norm. We are seeing how social media-Instagram, Facebook, TikTok, and Twitter-bombard us with thousands of images. Images and graphics are now important for online and printed articles, different from years past when only text was included. One can argue that society has become dependent on the visual. For this reason, scientists are now obligated to contribute their findings in visual form, with the critical caveat that our visuals be informative and honest. Creating a graphic should no longer be considered tangential. Teaching the research community and its students how to develop more effective visual data should be a primary goal.

Images are no longer just pretty pictures but play an essential role in communicating concepts, opening an accessible door to understanding scientific research. 


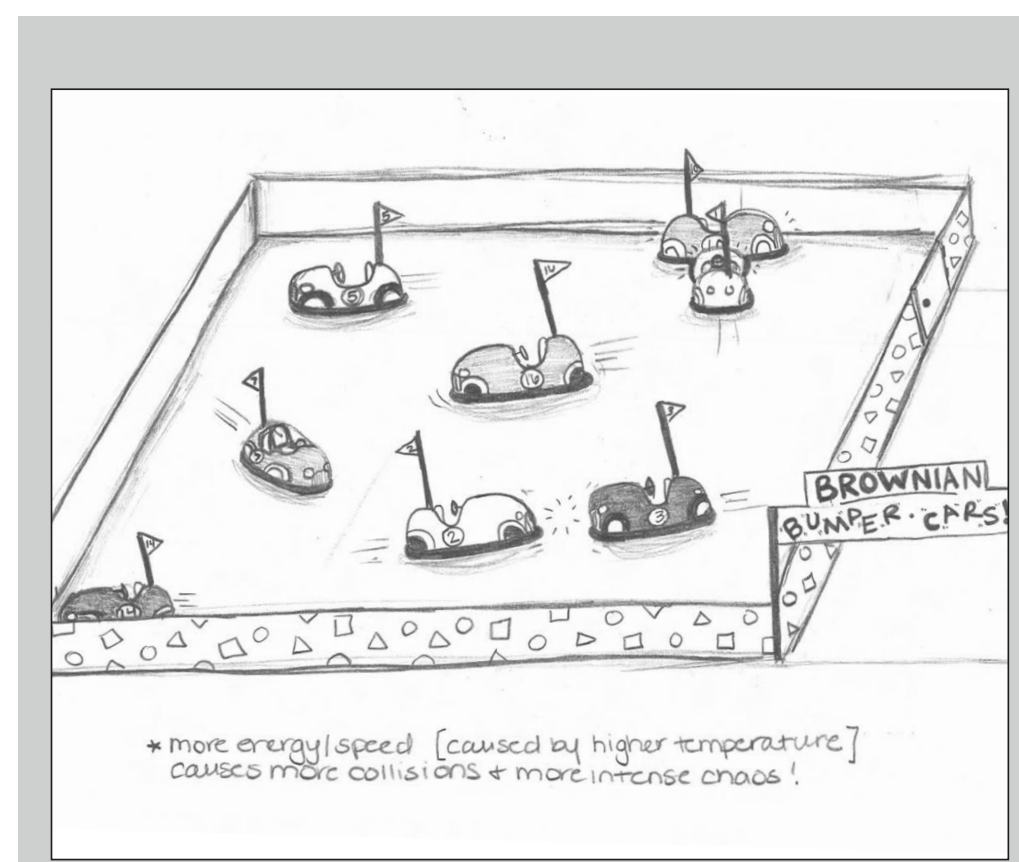

Figure 5. An illustration from the Picturing to Learn program.

\section{Table II. Misconceptions in drawing, labels, and/or captions.}

\author{
Misconceptions \\ (correct answers in parenthesis)
}

Role of fluid is switched with the role of the small particles.

(Fluid and small particles have different roles.)

\section{Frequency}

(Larger particles have smaller velocities than smaller ones.)

Particle motion is the result of collisions with fluid. (Particle motion is the result of collisions with smaller particles.)

Emphasis is on particle-to-particle collision instead of fluid-to-particle collision.

(Fluid-to-particle collision is more important in Brownian motion.)

Suspended particles and fluid are drawn on the same scale.

(Fluid particles are smaller than suspended particles.)

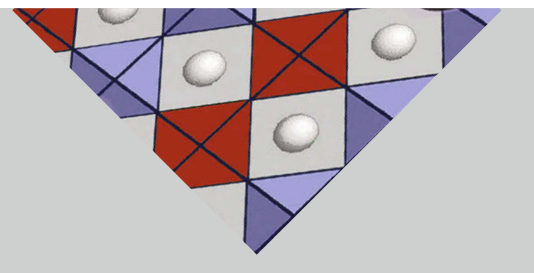

Table I: Summary report from the Picturing to Learn program.

\begin{tabular}{|c|c|}
\hline $\begin{array}{c}\text { Problematic misconceptions } \\
\text { about key concepts } \\
\text { Particle motion }\end{array}$ & Frequency \\
\hline Role of fluid & 50 \\
\hline Temperature change & 29 \\
\hline Particle size & 10 \\
\hline Basic terminology & 9 \\
\hline $\begin{array}{c}\text { Problematic omissions } \\
\text { of key concepts }\end{array}$ & Frequency \\
\hline
\end{tabular}

\begin{tabular}{|c|c|}
\hline Particle size & 56 \\
\hline Particle motion & 44 \\
\hline Role of fluid & 36 \\
\hline Temperature change & 7 \\
\hline
\end{tabular}

Table III. Omissions of critical components.

\begin{tabular}{|c|c|}
\hline Omissions & Frequency \\
\hline Comparison of different sized particles & 55 \\
\hline Collision & 30 \\
\hline Comparison of size with speed & 23 \\
\hline Fluid & 20 \\
\hline Relaionship between fluid and particles & 14 \\
\hline Change in temperature & 5 \\
\hline
\end{tabular}

8

\section{References}

1. A. Nasto, M. Regli, P.T. Brun, J. Alvarado, C. Clanet, A.E. Hosoi, "Air Entrainment in Hairy Surfaces," Phys. Rev. Fluids 1, 3 (2016).

2. S.W. Pattinson, M.E. Huber, S. Kim, J. Lee, S. Grunsfeld, R. Roberts, G. Dreifus, C. Meier, L. Liu, N. Hogan, A.J. Hart, "Additive Manufacturing of Biomechanically Tailored Meshes for Compliant Wearable and Implantable Devices," Adv. Funct. Mater. 29, 1901815 (2019).

3. N. Tsvetkov, Q. Lu, L. Sun, E.J. Crumlin, B. Yildiz, "Improved Chemical and Electrochemical Stability of Perovskite Oxides with Less Reducible Cations at the Surface," Nat. Mater. 15, 1010 (2016).
4. F.C. Frankel, Picturing Science and Engineering (MIT Press, Cambridge, MA, 2020).

5. A.J. Vegas, O. Veiseh, M. Gurtler, J.R. Millman, F.W. Pagliuca, A.R. Bader, J.C. Doloff, J. Li, M. Chen, K. Olejnik, H.H. Tam, S. Jhunjhunwala, E. Langan, S.A. Dasilva, S. Gandham, J.J. McGarrigle, M.A. Bochenek, J.H. Lock, J. Oberholzer, D.L. Greiner, G.C. Weir, D.A. Melton, R. Langer, D.G. Anderson, "Long-Term Glycemic Control Using Polymer-Encapsulated Human Stem Cell-Derived Beta Cells in Immune-Competent Mice," Nat. Med. 22, 3 (2016) 